\title{
A METHOD FOR GROWING LARGE SINGLE CRYSTALS OF SEA ICE
}

\author{
By TOSHIYUKI KAWAMURA*
}

(Sea Ice Research Laboratory, Institute of Low Temperature Science, Hokkaido University, Mombetsu,

Hokkaido 094, Japan)

ABSTRACT. A simple technique is presented for growing large single crystals of sea ice. Using this technique, crystals with dimensions of $20 \mathrm{~cm} \times 20 \mathrm{~cm} \times 10 \mathrm{~cm}$ or more can be readily obtained within an orientational accuracy of $3^{\circ}$. Such crystals can then be used to investigate the physical properties of sea ice.

RÉSUMÉ. Une méthode de croissance de grands cristaux de glace de mer. Une technique simple est présentée pour faire croître de grands monocristaux de glace de mer. Par cette technique, des cristaux de $20 \mathrm{~cm} \times 20 \mathrm{~cm} \times 10 \mathrm{~cm}$ ou

\section{INTRODUCTION}

As a useful tool in gaining an insight into the variations of the physical properties of a polycrystalline material, scientists have commonly studied the variations in the properties of single crystals of the same substance. This method has been widely used in investigations of pure ice, the single crystals being either collected from glaciers or grown artificially. Although strong horizontal $c$-axis orientations with a preferred azimuthal alignment have been observed near the bottom of sea-ice sheets (the standard deviations of the individual $c$-axis directions are usually about $10^{\circ}$ in the horizontal plane and $2-3^{\circ}$ in the vertical (Weeks and Gow, 1978)), to date such ice has only received limited study. Since natural oriented samples of this ice are usually difficult to obtain, it is useful to be able to grow such ice artificially. This paper describes a simple method for growing large single crystals of sea ice.

\section{PROCEDURE}

The procedure for growing a single crystal of sea ice consists of the following three steps. First, de-ionized water was frozen from above in a large commercially obtainable vessel whose walls and bottom were wrapped with insulation $5 \mathrm{~cm}$ thick. Relatively large single crystals were obtained at a low growth rate (approximately $0.5 \mathrm{~mm} / \mathrm{h}$ ), especially in the initial stage of freezing. Since the quantity of bubbles captured in the ice increased with ice thickness, only the top $3 \mathrm{~cm}$ of ice was used. Grains with vertical $c$-axes could then be determined by examining the etch-pit figures on the ice surface (Higuchi, 1958). On the basis of these figures, grains were then sliced vertically at intervals of approximately $8 \mathrm{~mm}$, using a band saw.

Secondly, the several oriented ice plates thus produced were laid parallel to each other, as shown in Figure 1, with all the $c$-axes oriented in the same direction in the horizontal plane. This multi-segmented seed was then floated on

* Present address: Institute of Low Temperature Science, Hokkaido University, Sapporo 060, Japan. plus peuvent être obtenus avec une précision d'orientation de 3 . De tels cristaux peuvent alors être utilisés pour déterminer les propriétés physiques de la glace de mer.

ZUSAMMENFASSUNG. Eine Methode zur Erzeugung grosser Einkristalle von Meereis. Für die Erzeugung grosser Einkristalle von Meereis wird eine einfache Technik vorgestellt. Damit können Kristalle von der Grösse $20 \mathrm{~cm} \times$ $20 \mathrm{~cm} \times 10 \mathrm{~cm}$ oder mehr innerhalb einer Orientierungsgenauigkeit von $3^{\circ}$ leicht gewonnen werden. Solche Kristalle stehen dann zur Untersuchung der physikalischen Eigenschaften des Meereises zur Verfügung.

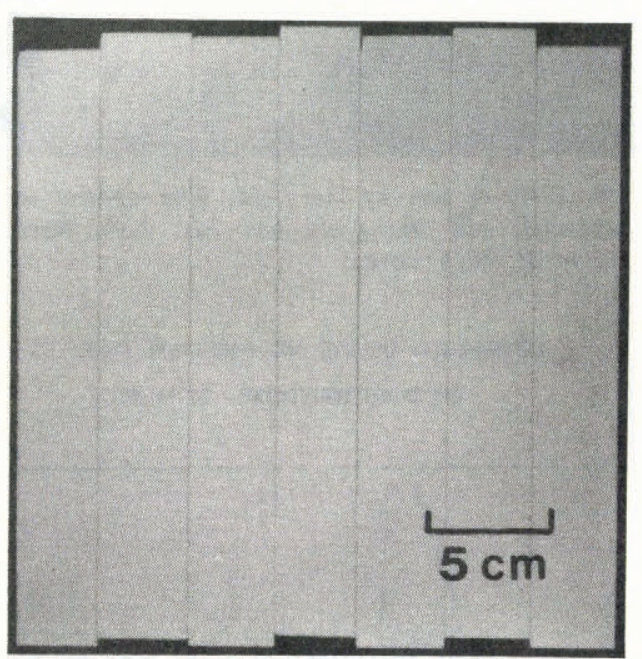

Fig. 1. Seed-ice plates laid parallel to each other to grow a pure-ice single crystal.

pure water in the vessel, allowing the plates to adhere to each other through the development of a liquid film. In floating the plates, great care must be taken not to capture air bubbles between the ice-water interface, because such bubbles could influence further ice growth. Care was also taken not to wet the upper surfaces of the plates in order to keep the $c$-axes parallel to the water surface. Moreover, the plates were placed on water having a surface temperature at about $1{ }^{\circ} \mathrm{C}$ to prevent the growth of external crystals with undesirable orientations. Consequently, the lower ice surface was melted a little and the exotic crystals disappeared. After a slab containing a large single crystal of pure ice was grown to about $2 \mathrm{~cm}$ thick, it was removed from the vessel. Subsequently, the upper part (approximately $1 \mathrm{~cm}$ ) was removed and the lower surface was also smoothed. 
Finally, we floated the prepared seed crystal on sea-water, taking the same care as described above. Since grains with horizontal $c$-axes grow preferentially in sea ice (Perey and Pounder, 1958), the sea ice on the bottom of the seed will keep the same crystallographic orientation as the overlying seed regardless of ice-growth rate. Consequently, we obtained large single crystals of sea ice with horizontal $c$-axes from such procedures.

Under calm conditions, such as occur during laboratory experiments, we could condense the procedure to two steps by using sea-water instead of pure water in the second step. However, since small discontinuities on the bottom surface between each plate may affect further ice growth, it is desirable to use the entire three-step procedure.

\section{ACCURACY OF SINGLE CRYSTAL}

Figure 2 shows a horizontal thin section of sea ice grown in the laboratory from a seed of pure ice $8 \mathrm{~mm}$

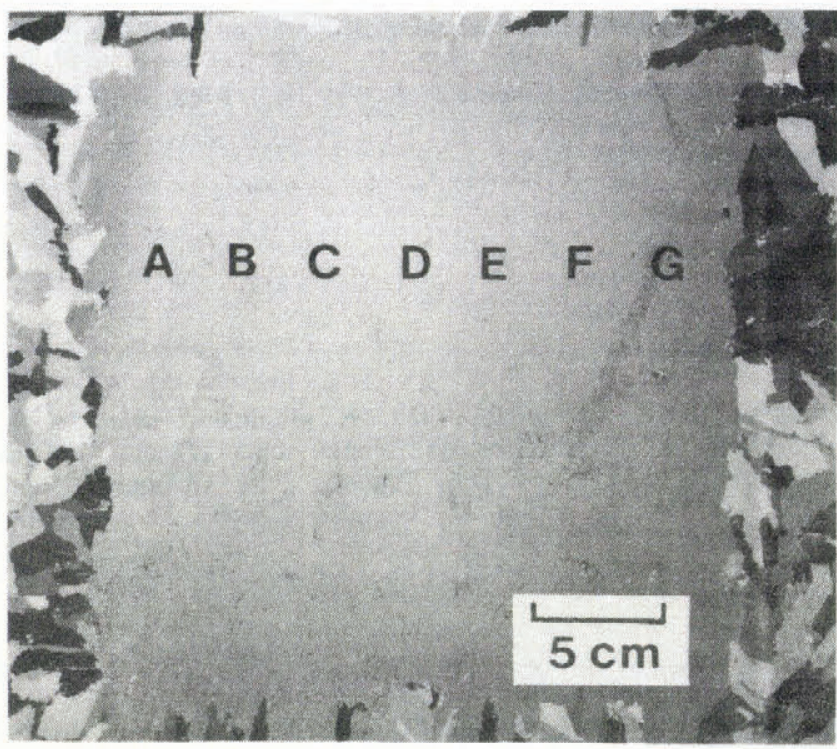

Fig. 2. Horizontal thin section of sea ice at a depth of about $5 \mathrm{~cm}$ below the upper surface. Laue $X$-ray photographs were taken at points from $A$ to $G$.

thick. No optical orientation differences could be recognized under polarized light in the large area in Figure 2.

Crystallographic orientations at points from $A$ to $G$ in Figure 2, corresponding to the almost central positions of the seed-ice plates, were determined with Laue X-ray photographs. Misorientations of both $c$-axes and $a$-axes as determined at both the adjacent points and the remote points are shown in Table $\mathrm{I}$, none of them exceeding $3^{\circ}$.

TABLE I. MISORIENTATIONS (DEGREES) OF $c$-AXES AND $a$-AXES BETWEEN THE ADJACENT POINTS FROM A TO G AND BETWEEN THE REMOTE POINTS A AND G IN FIGURE 2

$$
c-c
$$$$
a-a
$$

\section{A - B}

0.5

2.0

0.5

B - C

C - D

D - E

$E-F$

F - G
Although the orientations occasionally differed from each other even in the points grown from the same seed plate, probably due to the formation of sub-grains (Fukuda and others, 1983), the orientation differences between the adjacent sub-grains also did not exceed this value Therefore, the sea ice could be assumed to be a single crystal within these limits.

Grenfell and Perovich (1981) have produced bubble-free pure ice by growing it from the bottom up. The typical horizontal extent of their single crystals was $5-10 \mathrm{~cm}$ and the largest observed was $8 \mathrm{~cm} \times 20 \mathrm{~cm}$. If such ice were to be used as a seed in the second step of our procedure, the number of multiple segments could be reduced, and then more accurate single crystals of sea ice might be obtained.

\section{APPLICATIONS}

A single crystal of sea ice can be used for a variety of purposes. A grain in sea ice has been observed to exhibit a lamellar sub-structure consisting of platelets of pure ice lying perpendicular to the $c$-axes of the grain alternating with thin layers of brine. Therefore, this ordered alignment of the ice platelets and the brine pockets is undoubtedly responsible for the dependence of various physical properties of sea ice on the crystallographic orientation.

For example, Peyton (1966) investigated the orientation dependence of the tensile and the compressive strength of sea ice by using samples obtained near the bottom of a sheet of undeformed sea ice composed of grains with $c$-axes nearly parallel to each other. In addition, Kovacs and Morey (1978) observed in a field study near Narwhal Island, Alaska, that the reflection of an impulse radar signal from the bottom of sea ice is markedly dependent on the $c$-axis direction. However, such a phenomenon has not been investigated experimentally using well-oriented single crystals of sea ice grown artificially. Thus, the method described in this paper can be used to confirm experimentally these field observations (personal communication from F. Nishio).

\section{ACKNOWLEDGEMENT}

The author wishes to express his thanks to Dr W.F. Weeks for his extensive comments on the manuscript.

\section{REFERENCES}

Fukuda, A., and others. 1983. Kaihyō no akesshōryū no kesshōjiku-hōisa [Misalignment of crystal axes of subgrains in Antarctic sea ice], by A. Fukuda, Y. Ogawa, and M. Nakawo. Seppyo. Journal of the Japanese Society of Snow and Ice, Vol. 45, No. 4, p. 169-76.

Grenfell, T.C., and Perovich, D.K. 1981. Radiation absorption coefficients of polycrystalline ice from 400-1400 nm. Journal of Geophysical Research, Vol. 86, No. C8, p. $7447-50$.

Higuchi, K. 1958. The etching of ice crystals. Acta Metallurgica, Vol. 6, No. 10, p. 636-42.

Kovacs, A., and Morey, R.M. 1978. Radar anisotropy of sea ice due to preferred azimuthal orientation of the horizontal $c$ axes of ice crystals. Journal of Geophysical Research, Vol. 83, No. C12, p. 6037-46.

Perey, F.G.J., and Pounder, E.R. 1958. Crystal orientation in ice sheets. Canadian Journal of Physics, Vol, 36, No. 4, p. 494-502.

Peyton, H.R. 1966. Sea ice strength. College, AK, University of Alaska. Geophysical Institute. (UAG $\mathrm{R}-182$.

Weeks, W.F., and Gow, A.J. 1978. Preferred crystal orientations in the fast ice along the margins of the Arctic Ocean. Journal of Geophysical Research, Vol. 83, No. C10, p. 5105-21 